\title{
Application of Big Data Processing and Analysis Key Technology in Building Novel Model of Cross-Border E-Commerce
}

\author{
Hongsheng $\mathrm{Xu}^{1,}$ a and Ganglong Fan ${ }^{1}$ \\ ${ }^{1}$ Luoyang Normal University, Luoyang, 471934, China \\ a85660190@qq.com
}

\begin{abstract}
Keywords: Cross-border E-commerce; Big data; Electronic business platform; Data processing and analysis; B2B
\end{abstract}

\begin{abstract}
This paper first analyzes the cross-border e-commerce industry structure, and in-depth excavation of the characteristics of the electricity supplier model. Data processing system is the core of data analysis. In order to improve data analysis capabilities, cross-border electricity providers can introduce big data processing technology to seek cooperation and technical support. The paper presents application of big data processing and analysis key technologies in building novel model of cross-border e-commerce.
\end{abstract}

\section{Introduction}

With the rapid development of China's economy, all walks of life have accumulated a lot of criticism, so that it is difficult to break through the bottleneck period, foreign trade is also so. With the reform and opening up, joined the WTO, and it is after 10 years of development, gradually from the rising period into the bottleneck period. How to achieve a breakthrough in the bottleneck period, which is our new challenges, challenges and opportunities coexist, if twenty-first Centuries is the era of IT [1]. Then, we will immediately enter the era of big data, how to use a long history of foreign trade data to analyze the market, grasp the trend, is the key to break the deadlock, but also the opportunity to give us the times.

Big data can be seen from the literal meaning, it contains a huge amount of information, big data is the rapid development of information technology and technology products. Has the characteristics of social and extensive development of the era of big data, it can make the mobile e-commerce into a global information exchange can be large groups, industrial labor pattern information labor, labor mode in this product can be copied and transmitted by a lot of computer and electronic technology. The era of big data is to rely on the development of Internet technology, people's life and work basically can be converted to present data form, it revolutionized the way people work, into people's social life in every field to it.

With the rise of the Internet, data concept has changed fundamentally in early twentieth Century, mathematics, physics and other natural sciences has been the most widely used data field, then gradually extended to economics, enterprise management, the development of the Internet provides the possibility of massive and complex operation for processing data, then data extension continue to expand, in 2010 after the "cloud data" concept to break the limit of time and space data, big data era is opening up. B2C e-commerce is essentially a retail model, and the line than it is easier to obtain characteristics of consumer data, product data, several large domestic electricity supplier website has more than ten million level of active users.

With the development of big data, the entire electricity supplier industry needs solutions, not only for the consumer segment, but the upgrading of the industrial chain. In the future, the data will become a strategic asset [2]. Electricity supplier development after a lot of bonus stage, such as demographic dividend, dividend policy, flow bonus and so on, due to the occupation of giants, these bonuses have become the red sea. Where the new blue ocean mobile business prospects, data management era is is coming. For the electricity supplier, the data dividend can be from $\mathrm{C} 2 \mathrm{~B}, \mathrm{O} 2 \mathrm{O}$ and other Internet financial point of view to dig. 
Cross border e-commerce refers belong to different customs territory of the transaction subject, through e-commerce platform to achieve information or commodity trading of international commercial activities. According to the current cross-border electricity supplier model is different, the platform provides payment settlement, cross-border logistics services, financial services are different loan. In the cross-border electricity supplier market in accordance with the business model division, cross-border electronic business platform is divided into $\mathrm{B} 2 \mathrm{~B}, \mathrm{~B} 2 \mathrm{C}$ and $\mathrm{C} 2 \mathrm{C}$ three types. The paper presents application of big data processing and analysis key technologies in building novel model of cross-border e-commerce.

\section{Analysis of Business and Mode of Cross Border E-Commerce}

The cross-border retail refers to the transaction subject belong to different customs, with the aid of the computer network deal, payment and settlement, and the use of a parcel, express the way through cross-border logistics will reach the hands of consumers of the commodity trading process. Usually cross-border electricity supplier from the customs is equivalent to the sale of packets on the Internet, basically for consumers. In the strict sense, with the development of cross-border electricity supplier, a small portion of the sale of $B$ business users also include cross-border retail consumers, but this kind of $\mathrm{B}$ class $\mathrm{C}$ businesses and individual consumers in reality, it is difficult to distinguish, it is difficult to define the strict boundaries between the two, so, generally speaking, this part of the small B also belongs to the part of cross-border retail sales.

Cross-border electricity supplier export market growth will further focus on emerging markets, such as Latin America, Africa, Southeast Asia and other places. In Russia, for example, the number of Russian Internet users ranked first in Europe, reaching more than 7000. Among them, more than half of Russian Internet users have been online shopping. 2013, the Russian e-commerce market annual sales of more than 10 billion U.S. dollars, in 2014 China's cross-border network retail sales to Russia is expected to exceed $\$ 3$ billion 400 million. In addition, cross-border e-commerce in China's manufacturing sector will also improve the cross-border logistics system, the layout and construction of the sea than the sea, the growth will be explosive, as is shown by equation(1) [3].

$$
\xi_{i j}(k)=\left[1+\left|\frac{\Delta x_{i}(k)}{\sigma_{i}}-\frac{\Delta x_{j}(k)}{\sigma_{j}}\right|\right]^{-1}
$$

According to express or mail clearance of cross-border trade e-commerce problems to fast customs clearance, specification and refund, the General Administration of Customs Organization demonstration city to carry out cross-border trade e-commerce services pilot work on cross-border e-commerce related basic information standard specification, management system, improve the management and service level of customs clearance.

The development of such a remote transaction has created many difficulties for the tax authorities. The tax power can only be implemented strictly within a country, and the characteristics of the network bring difficulties to the tax authorities to exercise jurisdiction over the online transactions of a country [4]. And the internet sometimes acts as agency. In the traditional trading model often requires the presence of tangible sales outlets, for example, through the bookstore to sell the book to the reader, and online bookstores can replace the bookstore this sales outlets directly to complete the transaction. The problem is that the tax authorities tend to rely on these sales outlets to obtain the basic information needed to tax, withholding income tax. Without the existence of these sales outlets, the exercise of tax power will also be difficult.

Cross border electricity supplier is the main business model online display, online trading of foreign trade information service model. Cross border electricity supplier in the 1 stage of the main function of the third party platform is to provide information for enterprises and products to provide a platform for network display, as is shown by equation(2), where it is not involved in any transaction 
on the network. The profit model mainly through membership fees to the information display enterprise (such as service fee). Cross border electricity supplier in the 1 phase of the development process, but also gradually derived from the promotion of bidding, consulting services and other suppliers to provide one-stop information flow value-added services [5].

$$
b_{i}^{1}(t)^{*}=\left(1-c^{1}(t)\right)\left(1-d_{0}^{1}(t)\right) h_{i}^{1}(t) k_{i}^{1}(t)
$$

The system opened a $\mathrm{E}$ trade pilot platform, platform has attracted more than 3000 , including the South Korean Pavilion more than and 310, Israel Germany Pavilion Hall more than and 100 enterprises to conduct business in Zhengzhou docking, the platform has 319 enterprises settled. The main business model for cross-border trade E B2C marketing model, the sale of goods directly linked to cooperation with overseas manufacturers, the middle without any purchasing, distribution link directly to consumers, to ensure the authentic goods import quality.

Cross border electricity supplier turnover of goods by way of express transportation into or out of the country. The General Administration of Customs of the country's 5 largest express company survey shows that over $95 \%$ of the goods shipment is in accordance with the import and export of goods to the customs declaration, the customs statistics into the goods category, only less than 5\% of the proportion of personal articles according to the customs declaration, according to the customs statistics system, this part is not included in the Customs Trade Statistics temporarily, as is shown by equation (3).

$$
x_{i+1}^{2}(t+1)=\left(1-d_{i}^{2}(t)\right) x_{i}^{2}(t)+\left(\frac{N^{2}(t)}{N^{3}(t)+N^{2}(t)}\right) s_{i} \alpha N^{1}(t)
$$

It is difficult to identify the identity and location of e-commerce users because of the non centrality and global characteristics of cross-border e-commerce [6]. Online transactions consumers often do not show their true identity and their geographical location, it is important that this does not affect the transaction; the anonymity of the network also allows consumers to do so. In the virtual society, asymmetric concealed identity convenience immediately leads to freedom and responsibility. People here can enjoy the greatest freedom, but only the minimum responsibility, or even escape responsibility.

First, the cross-border electricity supplier 3 has a large factory on the line, B class buyers into the scale, the proportion of large orders to improve, large service providers to join the outbreak of mobile users and the characteristics of the five areas. At the same time, cross-border electricity supplier 3 services to upgrade the platform bearing capacity is stronger, the whole industry chain services online is also an important feature of the era of 3.

B2B: in the cross-border electricity supplier export scale of the export situation, export of general trade according to the nature of goods still belongs to the traditional trade, process specification, operation is relatively mature; mode of export in the debris case, by express mail and exit, it is difficult to get to the formal customs declaration, the problems existing in the security clearance, settlement and tax rebates.

\section{Application of Big Data Processing and Analysis Key Technologies in Building Novel Model of Cross-Border E-Commerce}

Big data requires more proactive management, but also need more innovation. For electricity supplier companies, in front of the site if people just click on the amount of data, they seldom pay attention to the back-end business data; trading links operate the web site the back-end staff only knows to sell things and seldom pay attention to the front-end data; behavior data and business data without docking [7]. This website, decision makers don't know behavior features of the site core user base, also do not know how to expand the scale of core users, but do not know from a user login website to leave what links need to dredge, the electricity supplier is not far away from the closure.

Cross border e-commerce is based on the development of the network, the network space is a new space relative to the physical space, is a virtual and objective existence of the world by the URL and 
password. The unique value standard and behavior mode of the network space have a profound impact on the cross-border e-commerce, which makes it different from the traditional trading mode and presents its own characteristics [8].

Modeling and analysis of the basic balance, the basic analysis is mainly based on simple data processing, on the growth, trends, pooled analysis index is accounted for, does not involve complex processing methods, too easy; and the need for huge amounts of data or make long-term predictions, the correlation effect of data processing, basic analysis it is difficult to achieve the purpose, such as to make the sales time series analysis requires the use of seasonal adjustment method, which requires the use of an appropriate data model, data model is formed based on a series of assumptions on the many assumptions is not established in reality.

$\mathrm{C} 2 \mathrm{C}$ e-commerce is the e-commerce between individuals and individuals. $\mathrm{C} 2 \mathrm{C}$ is Customer (Consumer) to Customer (Consumer). Mainly through the third party trading platform is to achieve personal electronic transactions on the individual cross-border $\mathrm{C} 2 \mathrm{C}$ [9]. In this report, cross-border $\mathrm{C} 2 \mathrm{C}$ refers belong to different customs territory of the individual sellers to carry out online sales of products and services for the individual buyer, by individual sellers through the third party business platform release products and services for sale price of product information, etc., the individual buyer for screening, the final through electronic business platform deal, payment and settlement, an international business the activities and delivery of goods through cross-border logistics, the completion of the transaction.

China's cross-border e-commerce is mainly divided into business to business (B2B) and business to consumer (B2C) trade model. B2B mode, the use of e-commerce and advertising information release, the transaction and customs clearance process basically completed online, is still a traditional trade, has been included in the general trade customs statistics. B2C, China's enterprises directly to foreign consumers, sales of consumer goods, logistics mainly by air parcel, express mail, etc., its declaration is the main postal or courier companies, are not included in the customs registration..

\section{Experiments and Analysis}

Electricity providers do consumer finance threshold is relatively high. On the one hand, large data mining problems, a single electricity supplier may become the data "island", the consumption data is not enough to reflect the user's entire credit system, the user portrait is not complete, the need to open up the data is valid [10]. On the other hand, the electricity supplier to do high risk such as consumer finance, the central bank's credit opening may only for banks and financial institutions are unlikely to use cost of the electricity supplier open at the same time, the fund is relatively high, but also spend a lot of energy to control the bad debts.

E-C is based on the different stages of user purchase decision. A standard purchase process, has experienced "home page browse / search, browse the product details page merchandise into the shopping cart -- a comparison of several successful payment links, users are in different stages of decision-making at each node. We set out from the dimensions (attribute data) and indicators (behavioral data), as is shown by equation (4), where it is to the user clustering, such as "received a coupon, but not used," the user to take precise push. We provide the API from the GrowingIO export these users ID and attributes, and then docking enterprise content CRM or EDM for precise push and reminder to stimulate the user's conversion.

$$
f(b)-f(a)=\frac{f^{\prime}\left(x_{1}\right)}{2 x_{1}}\left(b^{2}-a^{2}\right)
$$

The development of big data is bound to spread in all walks of life in the future. This popularity will be more obvious with the passage of time; there has been a concept that the forefront of foreign countries in China will hate the popularity of e-commerce, as early as the study abroad. From the experience of the past, we can get, learn from the West we can go faster, better. Big data in the West there are many typical cases, such as supermarket shopping, the chairman of the election, the unrest 
analysis, they will be a lot of information through analysis and calculation, and then combined with the algorithm, get useful data.

E-commerce is characterized by online real-time, dynamic sales. Customer visits and purchases of liquidity, tight goods sales will grow rapidly, the formation of exponential distribution. At the same time, the platform of information management system will accumulate a large amount of data, the formation of a large economic value and social significance of large data. Deep excavation, the study of e-commerce business law, improve sales, there is a positive significance.

\section{Summary}

The paper presents application of big data processing and analysis key technologies in building novel model of cross-border e-commerce. Cross border electricity supplier B2B import and export of cross-border electricity supplier B2B overall situation is basically the same. In the case of large-scale imports of goods, the general trade import by way of goods still belongs to the traditional trade, process specification, the operation is relatively mature.

\section{Acknowledgements}

This paper is supported by Henan key Laboratory for Big Data Processing \& Analytics of Electronic Commerce, and also supported by the science and technology research major project of Henan province Education Department (13B520155, 17B520026).

\section{References}

[1] Sirivimol Thanchalatudom, Namfon Assawamekin, Using Big Data Technology for Information Management in Hybrid Learning System, RNIS, Vol. 12, pp. 179 -182, 2013.

[2] Fan Yang, "The Research of E-Commerce Recommendation System Based on Cloud Computing", IJACT, Vol. 4, No. 16, pp. $256 \sim 263,2012$.

[3] Rodrigo Rocha Silva, Celso Massaki Hirata, Joubert de Castro Lima, "Computing BIG data cubes with hybrid memory", JCIT, Vol. 11, No. 1, (2016), pp. 13 -30.

[4] Hongxin Wan, Yun Peng, "Clustering and Evaluation on Electronic Commerce Customers Based on Fuzzy Set", IJACT, Vol. 5, No. 3, pp. 199 206, 2013.

[5] Duolin Liu, "E-commerce System Security Assessment Based on Grey Relational Analysis Comprehensive Evaluation", JDCTA, Vol. 5, No. 10, pp. $279 \sim 284,2011$.

[6] Shoupu Wan, Yongjia Wang, Michael Recce, "A Case Study of the Internet Dynamics -From Big Data to Marketing Insights”, IJIIP, Vol. 5, No. 2, (2014), pp. 39-52.

[7] Dawei Sun, Ge Fu, Xinran Liu, Hong Zhang, "Optimizing Data Stream Graph for Big Data Stream Computing in Cloud Datacenter Environments", IJACT, Vol. 6, No. 5, pp. $53 \sim 65,2014$.

[8] Wei Li, Hongtu Zhang, Tingting An, "Optimal Decision-Making in E-Commerce Platform Based On Optimal Stopping Theory", JCIT, Vol. 8, No. 8, pp. 922 929, 2013.

[9] Yanqing Lv, Jianmin Gao, Zhiyong Gao and Hongquan Jiang, "Multifractal information fusion based condition diagnosis for process complex", Process Mechanical Engineering, (2012),pp.1-8.

[10] JinHui Lei, XianFeng Yang, "Construction the E-commerce Trading Platform Based on Rough Set Data Mining Technology", JCIT, Vol. 8, No. 3, pp. $460 \sim$ 469, 2013. 